Article

\title{
Filtration Performance Characteristics of Sticky Aerosol Using Calcium Hydroxide
}

\author{
Jae-Rang Lee ${ }^{1,2}{ }^{,}$Naim Hasolli ${ }^{1}$, Seong-Min Jeon ${ }^{1}$, Kang-San Lee ${ }^{1}$, Jun-Hyeok Gang ${ }^{1}$, \\ Kwang-Deuk Kim ${ }^{1}$, Kwan-Young Lee ${ }^{2}$ and Young-Ok Park ${ }^{1}$ * \\ 1 Climate Change Research Division, Korea Institute of Energy Research, 152 Gajeong-ro, Yuseong-gu, \\ Daejeon 34129, Korea; jehajr@kier.re.kr (J.-R.L.); nhasolli@kier.re.kr (N.H.); estjsm@kier.re.kr (S.-M.J.); \\ ksiya@kier.re.kr (K.-S.L.); kjh7692@kier.re.kr (J.-H.G.); kdkim@kier.re.kr (K.-D.K.) \\ 2 Department of Chemical and Biological Engineering, Korea University, 145 Anam-ro, Seongbuk-gu, \\ Seoul 02841, Korea; kylee@korea.ac.kr \\ * Correspondence: yopark@kier.re.kr
}

Received: 29 January 2019; Accepted: 22 February 2019; Published: 24 February 2019

\begin{abstract}
This study examined the performance of removing aerosol upon a flow rate variable by agglomerating sticky aerosol with calcium hydroxide and removing cohesive aerosol through an experimental apparatus, simulating an actual painting booth. As a result of examining the performance of the filter by fixing the paint spray quantity, the calcium hydroxide input and the filtration area under variable flow rates of 5,10 , and $15 \mathrm{Nm}^{3} / \mathrm{min}$, we confirmed that the filter performance has long average aerosol removing intervals at the $5 \mathrm{Nm}^{3} / \mathrm{min}$ flow rate. At the $5 \mathrm{Nm}^{3} /$ min flow rate, there is a low residual pressure drop trend and high fractional collection efficiency, and a high level of total collection efficiency is maintained at $99.42 \%$. When the flow rate is less than $5 \mathrm{Nm}^{3} / \mathrm{min}$, the aerosol settling and experimentation was impossible. With this research, the optimal conditions for the use of sticky aerosol have been examined.
\end{abstract}

Keywords: sticky aerosol; calcium hydroxide; flow rate; filter; total collection efficiency

\section{Introduction}

As air pollutants without known causes have been generated, and as human beings, the ecology, and nature are damaged with the rapid industrial development of the modern era, research on air pollution protection facilities has been carried out [1]. There are places that have been found to have various air pollutants, in which the emission of sticky aerosol and gaseous substances from painting booths such as VOCs (Volatile Organic Compounds) is a very serious problem [2,3]. A number of studies has been concerned with the removal of VOCs as gaseous substances from painting booths, but it is rare to find research on practically removing large quantities of sticky aerosol [4,5]. A method to remove aerosol generated from normal industrial sites is to collect it with a filter, remove the aerosol, and capture it using a hopper [6]. It is difficult to manage sticky aerosol from a painting booth, since the sticky aerosol has a crucial adverse effect on reducing the life of a filter, meaning it cannot perform its functions properly $[7,8]$. Although a wet removal technique and disposable filters are used to remove sticky aerosol from painting booths, they are not efficient due to the requirement of the secondary removal of wastewater or the frequent replacement of disposable filters. Research into the efficient removal of sticky aerosol from painting booths is required $[9,10]$.

This research agglomerated sticky aerosol with calcium hydroxide in an experimental apparatus imitating an actual painting booth to remove stickiness; collected it on a filter; and studied the cleaning efficiency, total collection efficiency, and fractional collection efficiency of the filter. The intention was to examine the filtration characteristics of the filter in detail and to obtain the optimal operation conditions to apply to actual painting facilities. 


\section{Material and Methods}

\subsection{Paint}

In this research we conducted the experiment with a painting method generally used in operations for partial painting, such as automobiles, ships, motor bikes, etc. Paint (Scandal Red, Jevisco) and thinner (DR-421W, Noroo paint) were mixed in a 1:1 ratio for the experiment. The paint substances for the experiment were analyzed with GC-MSD (Aglient, Santa Clara, CA, USA), and the analysis results are shown in Table 1, indicating that toluene represents the largest single component.

Table 1. Substance analysis results of paint for the experiment.

\begin{tabular}{cc}
\hline Compounds & Mole Fraction \\
\hline Toluene & 0.801 \\
m/p-Xylene & 0.042 \\
Butylacetate & 0.054 \\
Methyl Ethyl Ketone & 0.025 \\
Ethylbenzene & 0.065 \\
o-Xylene & 0.004 \\
Ethylacetate & 0.005 \\
Acetone & 0.004 \\
\hline
\end{tabular}

\subsection{Calcium Hydroxide}

The calcium hydroxide used in this research has been analyzed for its image and substances using a Scanning Electron Microscope (SEM) and Energy Dispersive Spectroscopy (EDS) (HITACHI, Tokyo, Japan), as shown in Figures 1 and 2. The substance analysis results show that calcium represents the largest component. Figure 1 shows that the shape of calcium hydroxide that was determined to have agglomeration for the experiment is in a non-spherical form. An SEM image analysis has been carried out, as it has been determined that it is possible to verify the shapes of viscous paint aerosol and calcium hydroxide on agglomerations when collected on a filter.

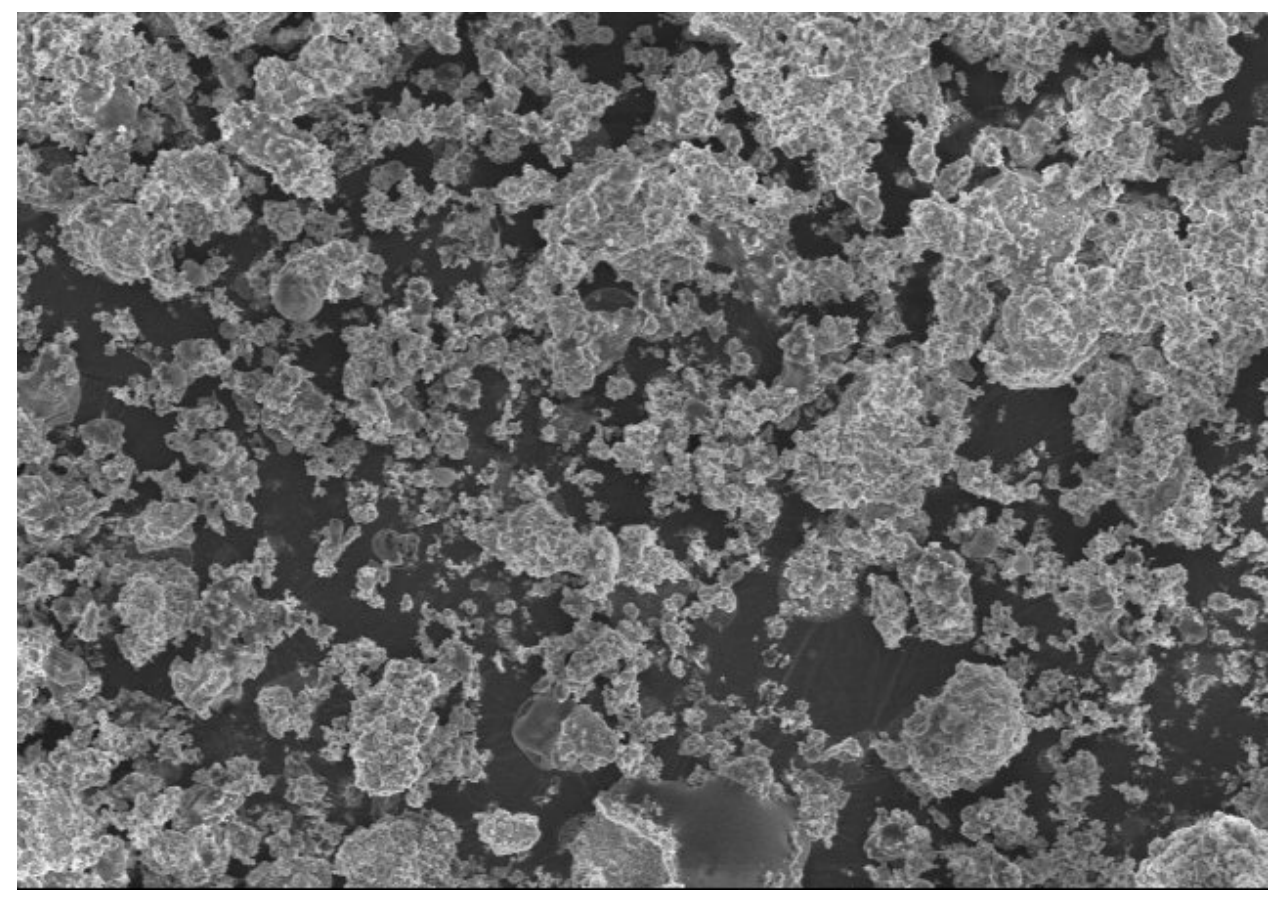

Figure 1. Cont. 


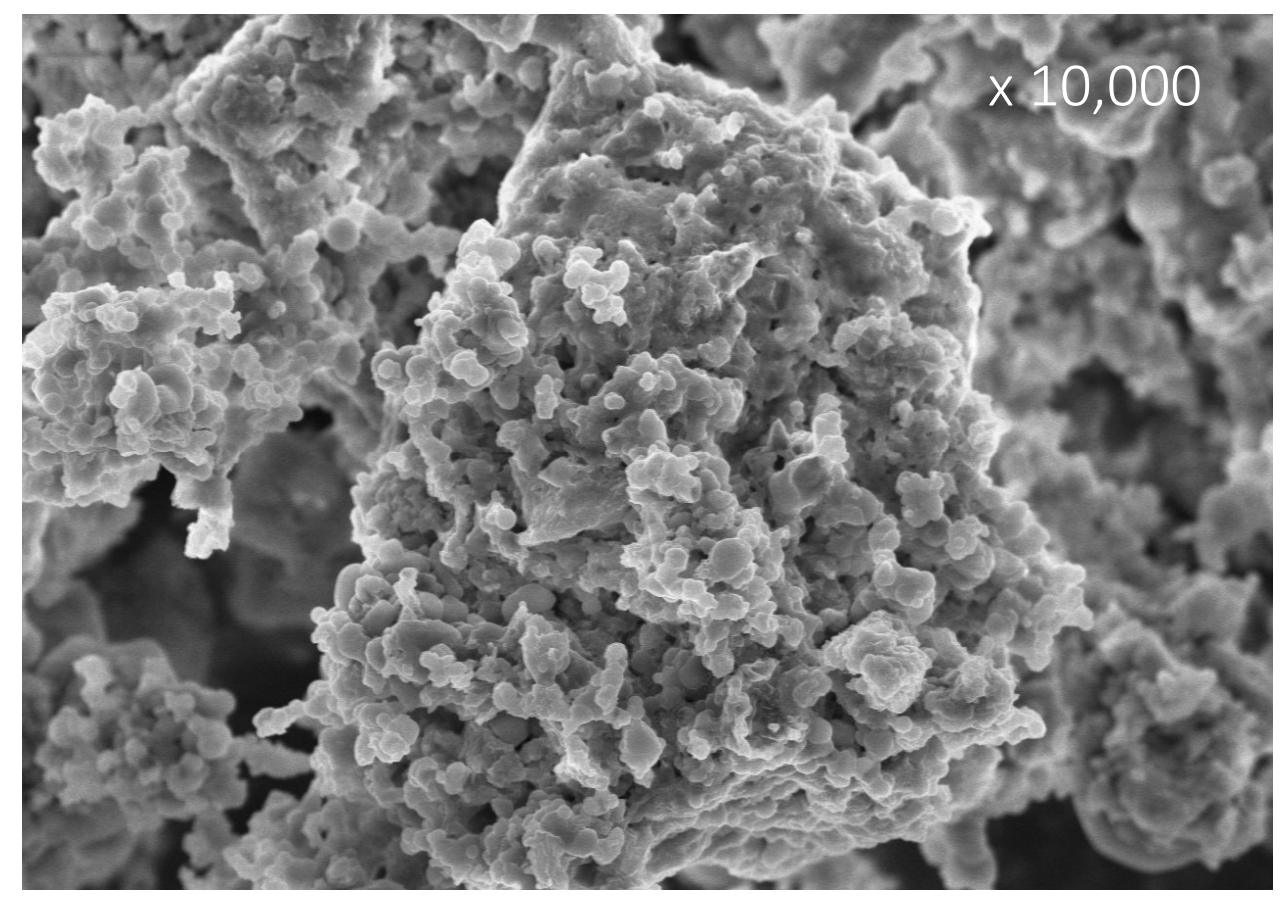

Figure 1. 1000 and 10,000 times magnified images of calcium hydroxide.

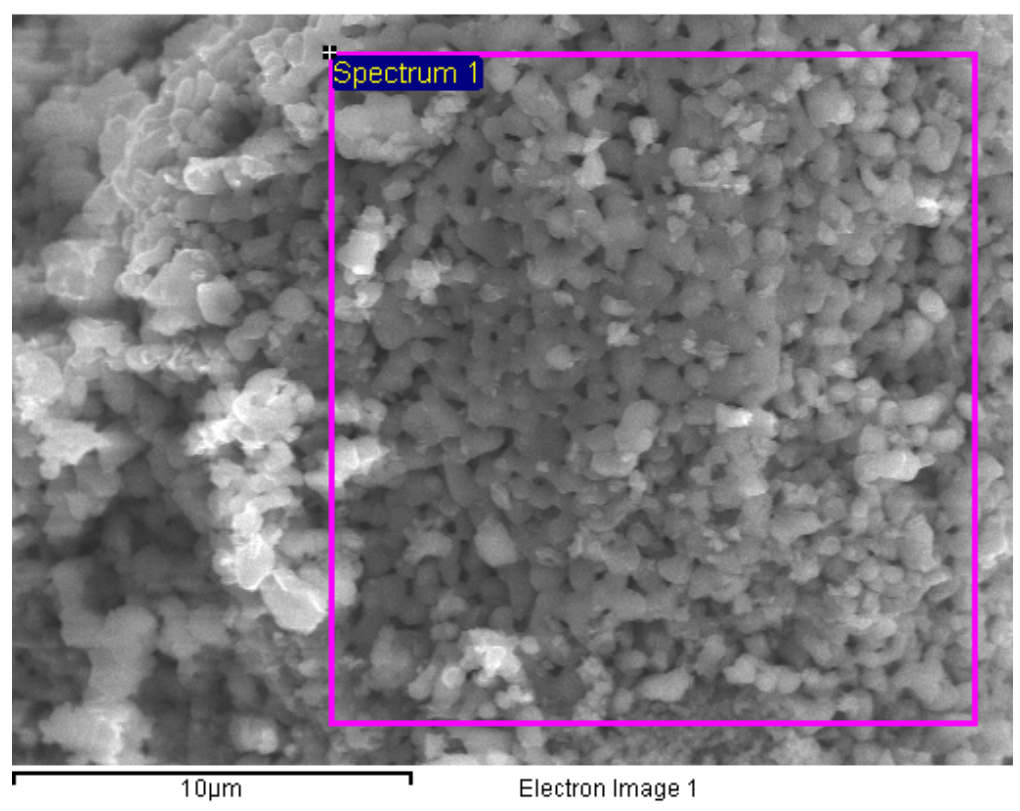

Figure 2. Cont. 


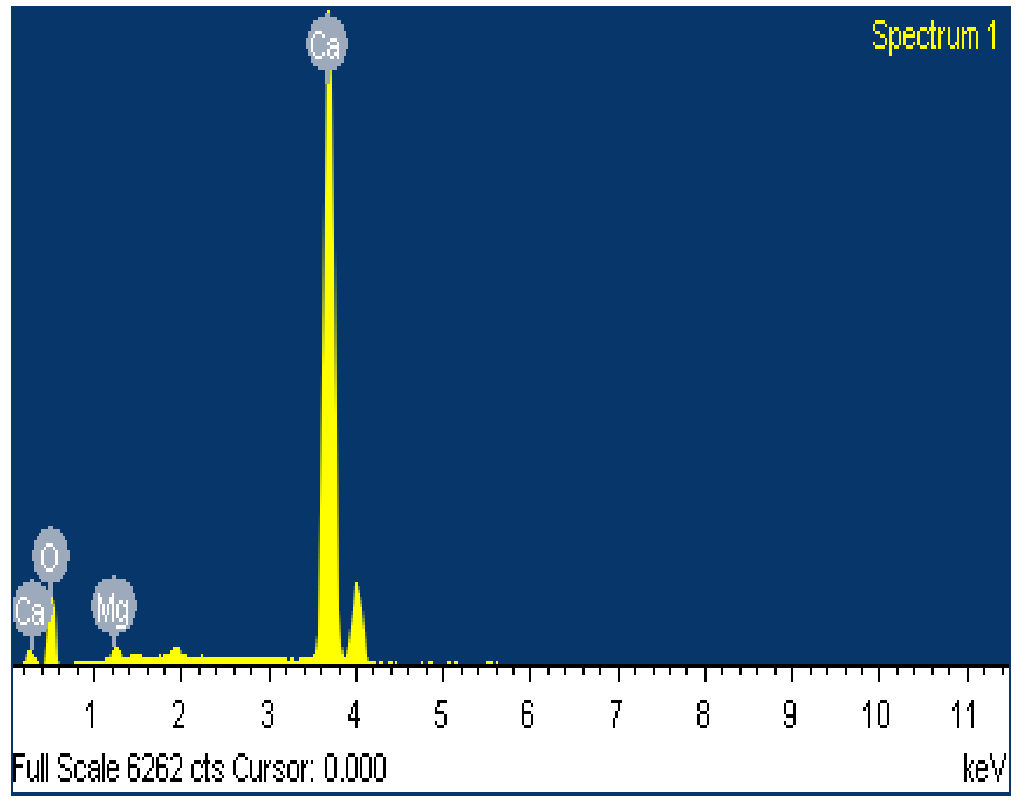

Figure 2. Substance analysis results of calcium hydroxide with EDS.

\subsection{Filter}

The specifications of the filter used in this research are shown in Table 2, and the appearance of its installation is shown in Figure 3. The filtration area of the filter is $8 \mathrm{~m}^{2}$, and the total filtration area of 4 filters is $32 \mathrm{~m}^{2}$, as used for the experiment.

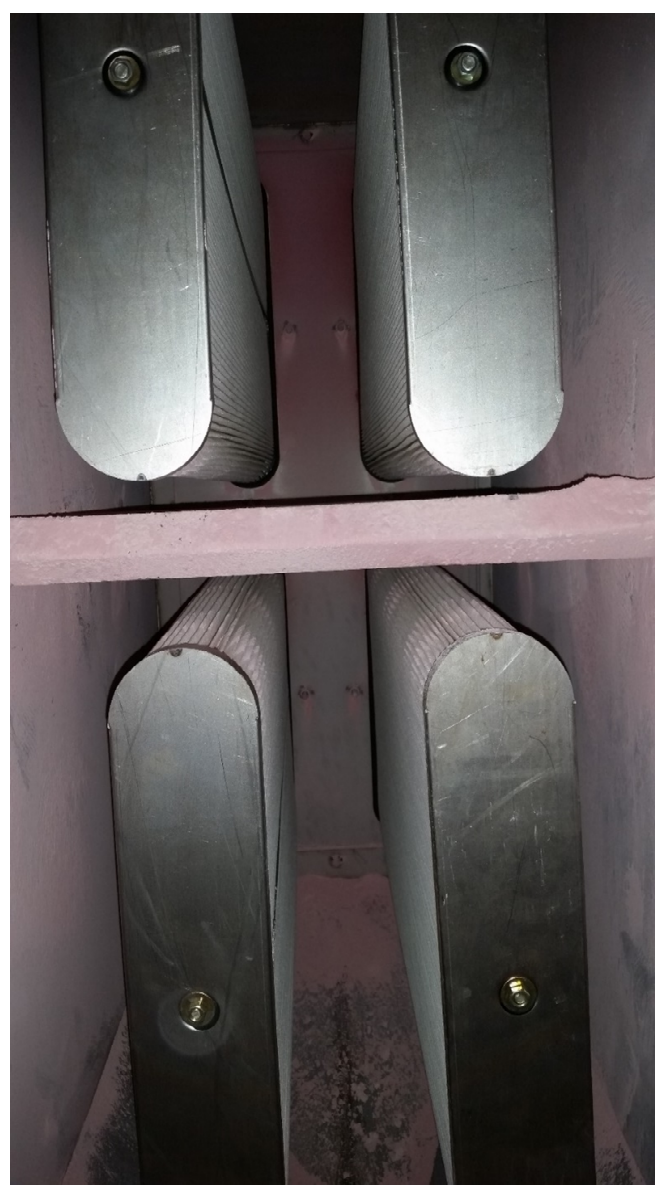

Figure 3. The scene of a filter installed in an apparatus for the experiment. 
Table 2. The specifications of the filter for the experiment.

\begin{tabular}{cc}
\hline Parameter & Value \\
\hline Filtration area & $32 \mathrm{~m}^{2}$ \\
Pleat number & 400 \\
Filter media material & Polyester, membrane coating \\
Filter thickness & $550 \mu \mathrm{m}$ \\
Quality of the filter media & PTFE $($ Polytetrafluoroethylene) \\
Air permeability & $7.5 \mathrm{~cm}^{3} / \mathrm{cm}^{2} / \mathrm{s}$ \\
Cartridge dimension & $494 \mathrm{~mm} \times 1050 \mathrm{~mm}$ \\
\hline
\end{tabular}

\subsection{Procedure}

The experimental conditions to remove the sticky aerosol are summarized in Table 3, and a flow diagram of the experiment and actual laboratory scene is shown in Figure 4 . The test equipment includes a painting booth, a spray gun, a coagulant supplier, an air compressor, a control box, and 2 lines of 2 filters installed. The paint was quantitatively sprayed in $10 \mathrm{~g} / \mathrm{min}$ under $2 \mathrm{~kg} / \mathrm{cm}^{2} \mathrm{of}$ compressed air in the painting booth, and the sticky aerosol is mixed with the calcium hydroxide to lose its stickiness in order to be captured in the filter. As the aerosol captured by the filter increases, the pressure drops over time due to the fluid build-up, with pulsing applied at certain intervals. As there were concerns about a fault of the aerosol spectrometer (GRIMM, Model 1.108), the aerosol was diluted using dilution equipment (Aerosol Diluter, Model DI-120) to 100 times in order to measure the inlet concentration. It was not diluted to measure the concentration at the outlet. In order to measure the pressure drop, pressure drop measurement ports were installed before and after the fluid passed through the filter, using an electronic remote differential pressure sensor (Differential pressure transmitter, Rosemount. Inc., West Florissant Avenue, Shakopee, MN, USA).

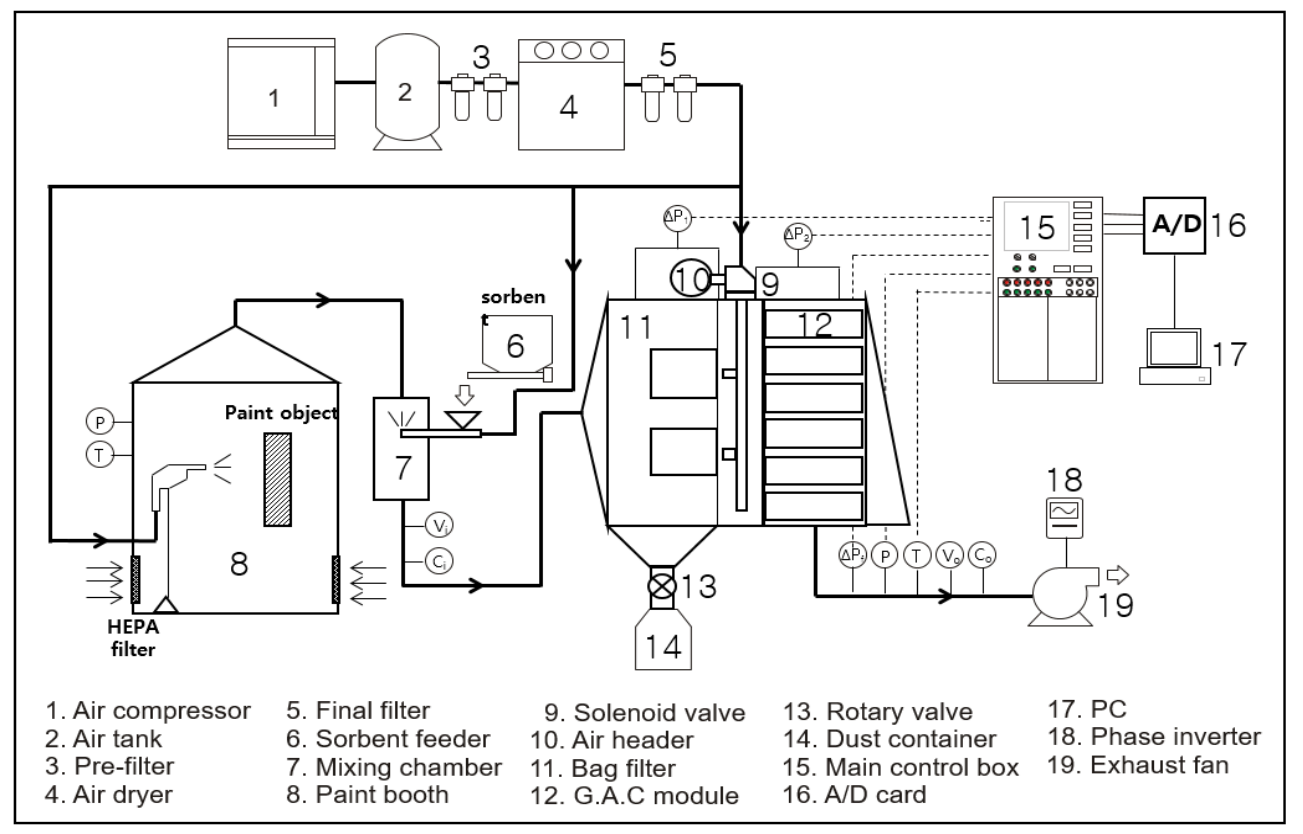

(a)

Figure 4. Cont. 


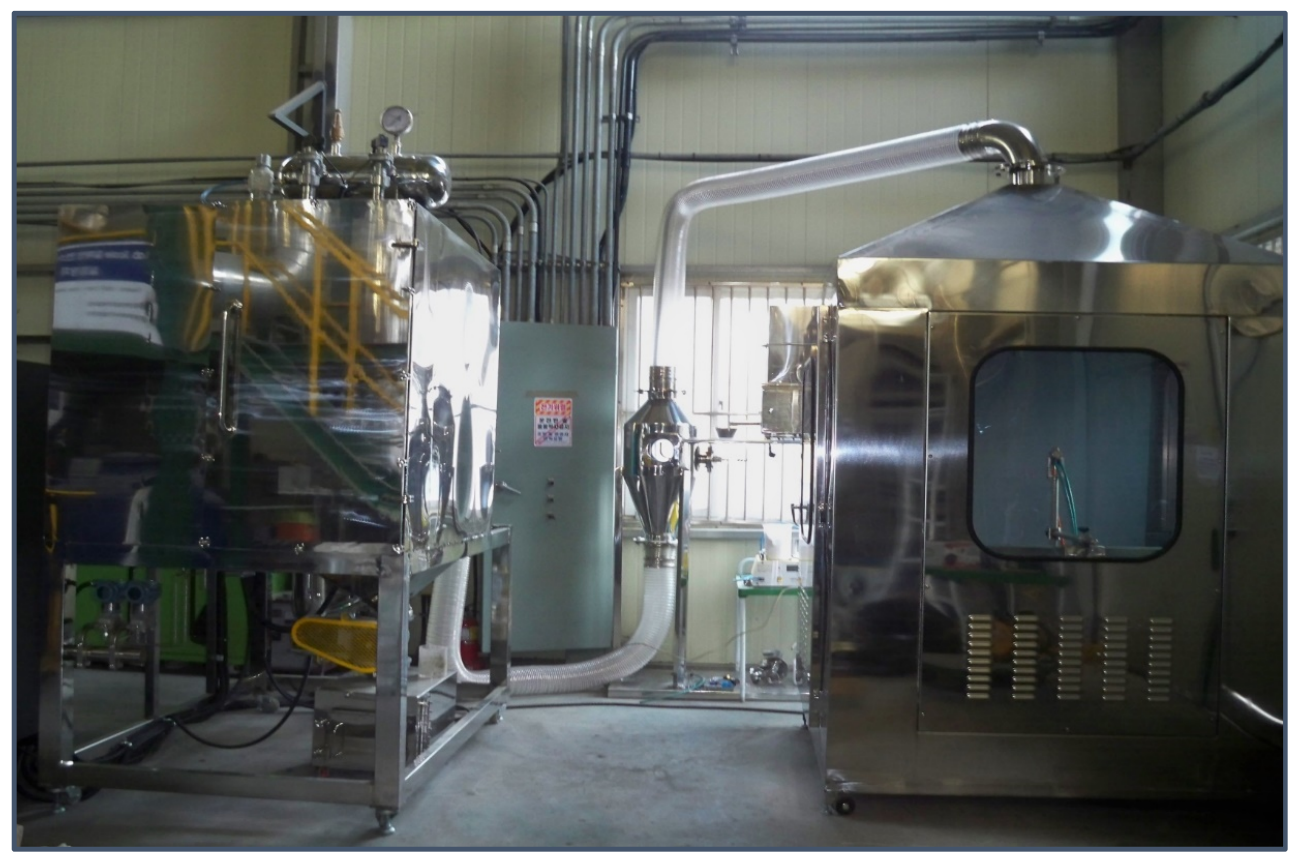

(b)

Figure 4. (a) Flow diagram and (b) scene of the actual laboratory.

Table 3. Summaries of the experimental conditions.

\begin{tabular}{cc}
\hline Parameter & Value \\
\hline Flow rate & $5,10,15 \mathrm{Nm}^{3} / \mathrm{min}$ \\
\hline Number of filter elements & 4 \\
\hline Type of filter & Bag filter \\
\hline Dimension of the filter & $\begin{array}{c}\text { Depth: } 494 \mathrm{~mm} \\
\text { Height: } 1050 \mathrm{~mm} \\
\text { Thickness: } 100 \mathrm{~mm}\end{array}$ \\
\hline Pulsing system unit & T-type pulse injector \\
\hline Cohesive agent type & Calcium hydroxide \\
\hline Feed rate of calcium hydroxide & $10 \mathrm{~g} / \mathrm{min}$ \\
\hline Feed rate of paint & $10 \mathrm{~g} / \mathrm{min}$ \\
\hline
\end{tabular}

\section{Results and Discussion}

\subsection{Theory}

A filter basically has a pressure drop due to the flow of fluid. Considering the entire system, the pressure drop of the filter is an important factor, as shown in Equation (1) below [11]:

$$
\text { Pressure drop of filter }=\left(64 \mu \mathrm{LU} \alpha^{\wedge} 1.5\left(1+56 \alpha^{\wedge} 3\right)\right) /\left(\mathrm{d} \_\mathrm{f}^{\wedge} 2\right)
$$

In Equation (1), $\mu$ is the viscosity of air, $\mathrm{L}$ is the filter thickness, $\mathrm{U}$ is the filtration velocity of the filter, $\mathrm{d} \_\mathrm{f}$ is the fiber diameter, and $\alpha$ is the solidity of the filter.

The total pressure drop of a filter is defined as the summation of the pressure drop of a filter (1) and the pressure drop of an aerosol layer, as shown in Equation (2) [12]:

$$
\Delta \mathrm{P}=\Delta \mathrm{Pf}+\Delta \mathrm{Pa}
$$


In Equation (2), $\Delta \mathrm{P}$ is the total pressure drop $\left(\mathrm{mmH}_{2} \mathrm{O}\right), \Delta \mathrm{Pf}$ is the pressure drop of a filter $\left(\mathrm{mmH}_{2} \mathrm{O}\right)$, and $\Delta \mathrm{Pa}$ is the pressure drop of the aerosol $\left(\mathrm{mmH}_{2} \mathrm{O}\right)$.

The total collection efficiency is the entire collection efficiency of the aerosol at the outlet per aerosol concentration of the aerosol at the inlet. The total collection efficiency is expressed as Equation (3) [13]:

$$
\text { Total collection efficiency }=(\text { Cin }- \text { Cout }) / \text { Cin } \times 100 \%
$$

In Equation (3), Cin is the aerosol concentration of the aerosol at the inlet $\left(\# / \mathrm{cm}^{3}\right)$, and Cout is the aerosol concentration of the aerosol at the outlet $\left(\# / \mathrm{cm}^{3}\right)$.

The efficiency according to the aerosol size of the aerosol refers to the fractional collection efficiency, as shown in Equation (4) [14]:

$$
\text { Fractional collection efficiency }=(1-\text { Cout } / \text { Cin }) \times 100 \%
$$

In Equation (4), Cin is the respective aerosol concentration of the aerosol at the inlet $\left(\# / \mathrm{cm}^{3}\right)$, and Cout is the respective aerosol concentration of the aerosol at the outlet $\left(\# / \mathrm{cm}^{3}\right)$.

\subsection{Cleaning Interval}

A function of a filter is to collect aerosol between its fibers with mechanisms of inertial collision and direct blocking. Based on Equation (2), as the pressure drop increases due to the aerosol, the aerosol must be twisted with an impacting air flow stuck on the filter, which refers to pulsing. The time between the first pulsing and the second pulsing refers to a cleaning interval $[15,16]$.

Figure 5 shows the results of the cleaning interval at the flow rates 5,10 , and $15 \mathrm{Nm}^{3} / \mathrm{min}$. After 3 times cleaning, the cleaning intervals at the flow rates 5, 10, and $15 \mathrm{Nm}^{3} / \mathrm{min}$ are 424,170 , and $105 \mathrm{~min}$, respectively. It has been checked that the lower the flow rate, the longer the cleaning interval.

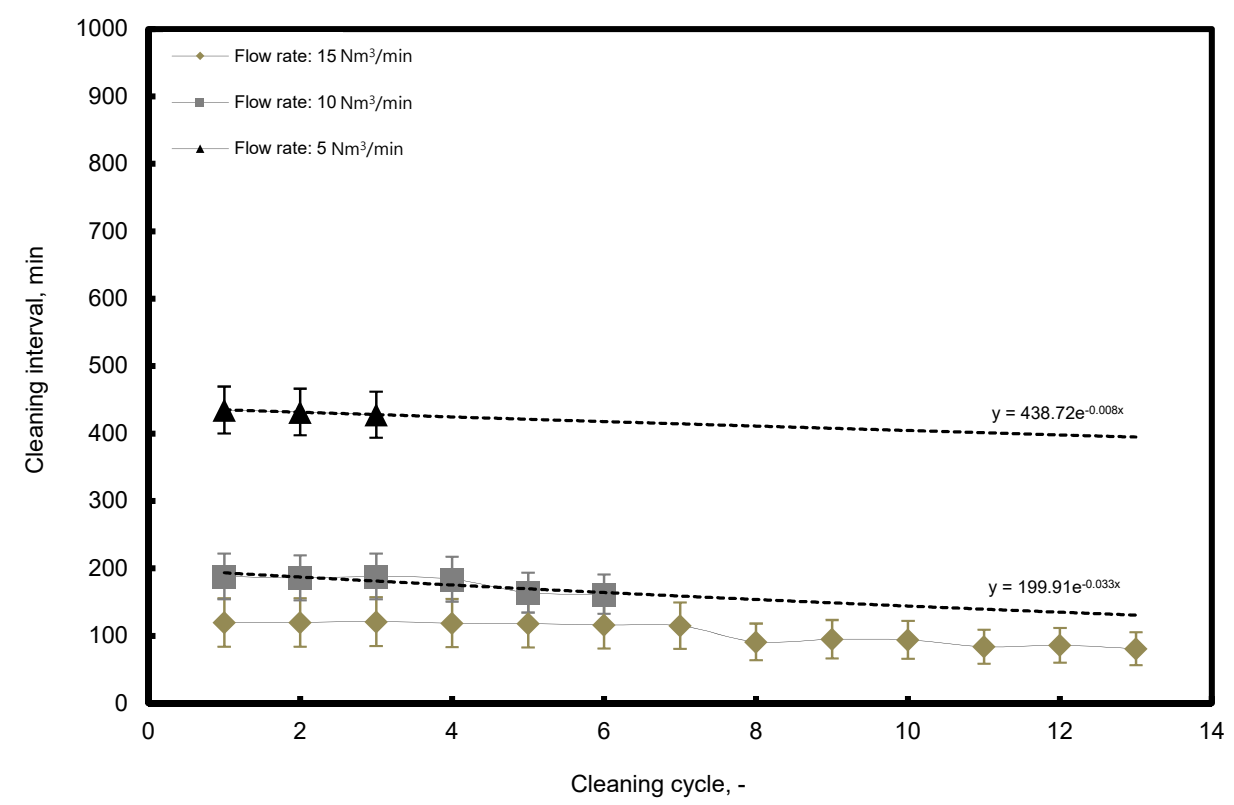

Figure 5. Cleaning interval results with the flow rate variable.

\subsection{Residual Pressure Drop}

A pressure drop value measured after the pulsing refers to the residual pressure drop [17]. Figure 6 shows a rapid increase at the flow rate $15 \mathrm{Nm}^{3} / \mathrm{min}$ as the cleaning times increase, and the relatively low flow rates 5 and $10 \mathrm{Nm}^{3} /$ min show slowly increasing results. Since a low flow rate has a low residual pressure drop, the aerosol must be removed at the low flow rate, considering operating costs and the efficiency of the equipment. 


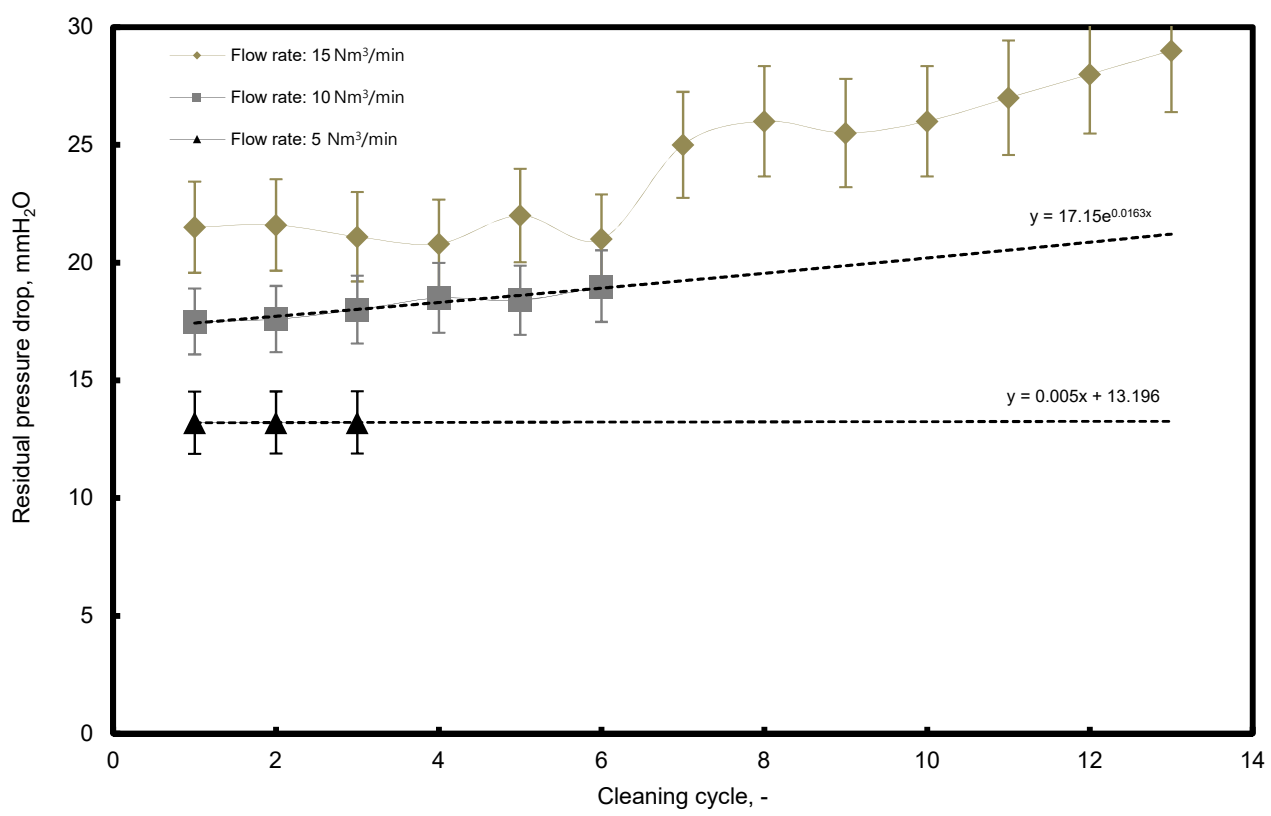

Figure 6. Residual pressure drop trend with flow rate variable.

\subsection{Cleaning Efficiency}

The cleaning efficiency can be determined as the aerosol captured on the filter after the cleaning operation. When a large amount of the aerosol has desorbed from a filter, it has a high cleaning efficiency. On the contrary, when a large amount of the aerosol remains on the filter after the deducting operation, its cleaning efficiency is defined as low $[18,19]$. Figure 7 shows that the average cleaning efficiencies at the flow rates 5,10 , and $15 \mathrm{Nm}^{3} / \mathrm{min}$ are $99.18,95.21$, and $89.9 \%$, indicating that the higher the flow rate, the lower the cleaning efficiency.

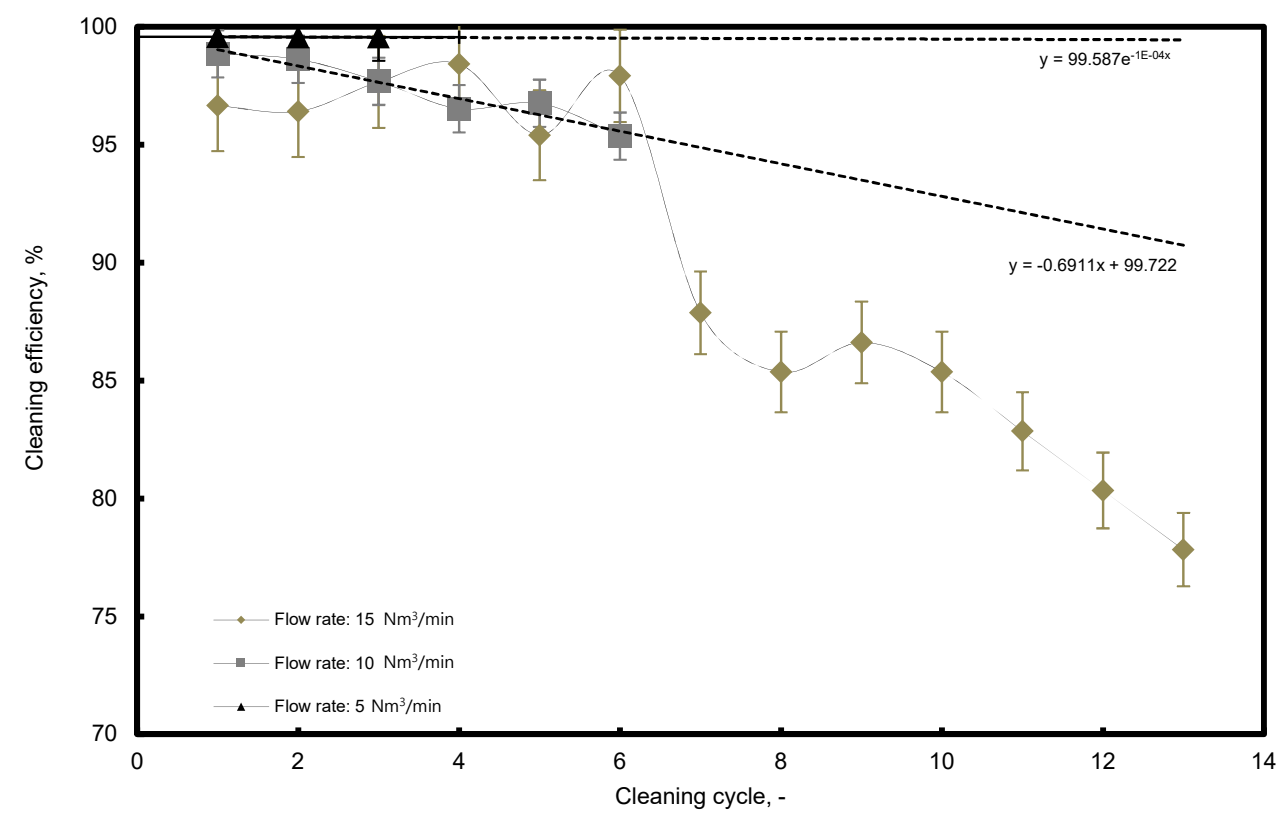

Figure 7. Cleaning efficiency results with flow rate variable.

\subsection{Collection Efficiency}

For research on the removal of air pollutants, the concentration of incoming and outgoing aerosol is the most important factor. The results of the total collection efficiency to determine the aerosol 
removing efficiency with the total aerosol concentration, and of the fractional collection efficiency to determine it with the aerosol size are important $[20,21]$. This research has measured the aerosol concentration in a range of aerosol sizes from 0.3 to $20 \mu \mathrm{m}$. Figure 8 shows the total collection efficiency, indicating 99.41, 90.98, and 83.37\% at the flow rates 5, 10, and $15 \mathrm{Nm}^{3} / \mathrm{min}$. Figure 9 shows the collection efficiency per aerosol size, indicating a low collection efficiency for aerosol sizes from 0.3 to $2 \mu \mathrm{m}$ at the flow rate $15 \mathrm{Nm}^{3} / \mathrm{min}$ used in this experiment. There is a similar collection efficiency with aerosol sizes from 2 to $20 \mu \mathrm{m}$ at the flow rates 10 and $15 \mathrm{Nm}^{3} / \mathrm{min}$. The features to remove aerosol have been examined at the flow rates 5,10 , and $15 \mathrm{Nm}^{3} / \mathrm{min}$. It was impossible to carry out the experiment under the flow rate $5 \mathrm{Nm}^{3} / \mathrm{min}$ due to the precipitation of aerosol, and difficult to find out result trends for over $15 \mathrm{Nm}^{3} / \mathrm{min}$. As a result, it was possible to get clear result trends for the experiment at 5 units of flow rate conditions.

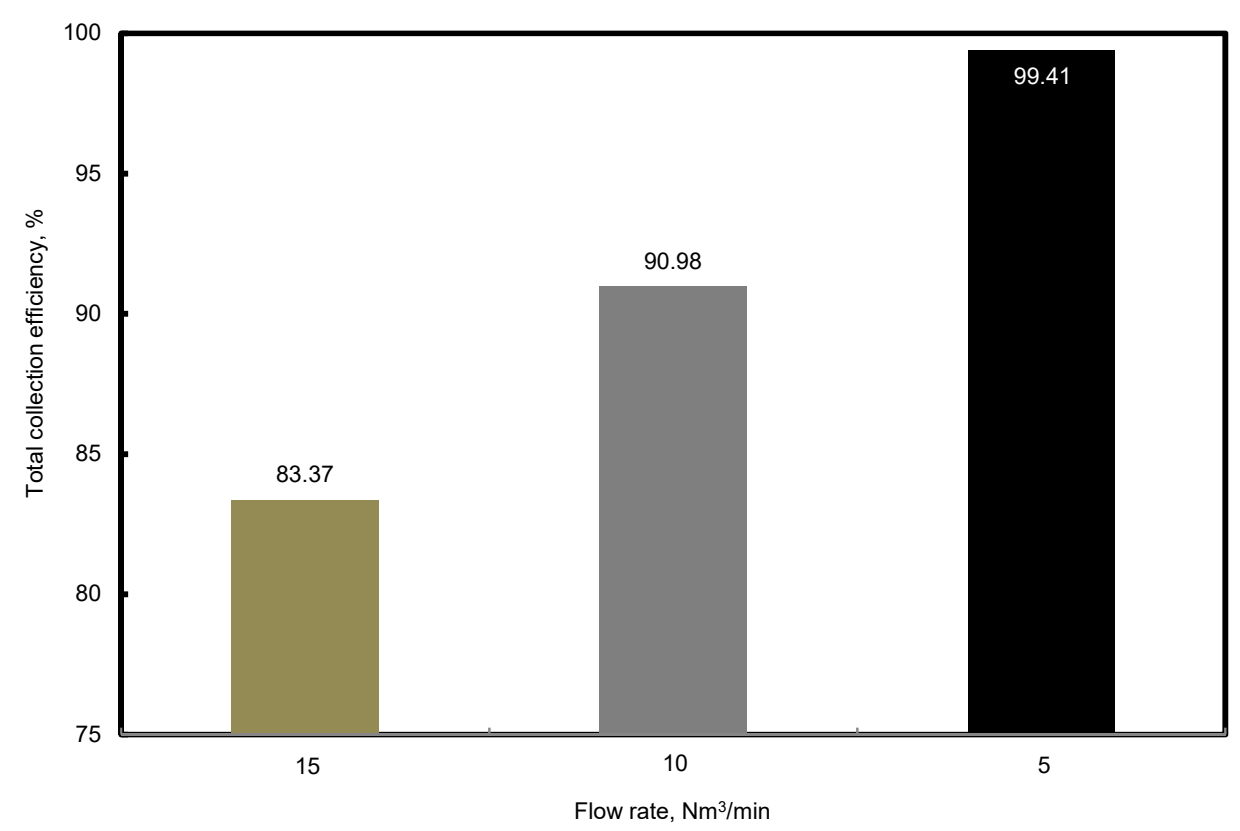

Figure 8. Total collection efficiency results with flow rate variable.

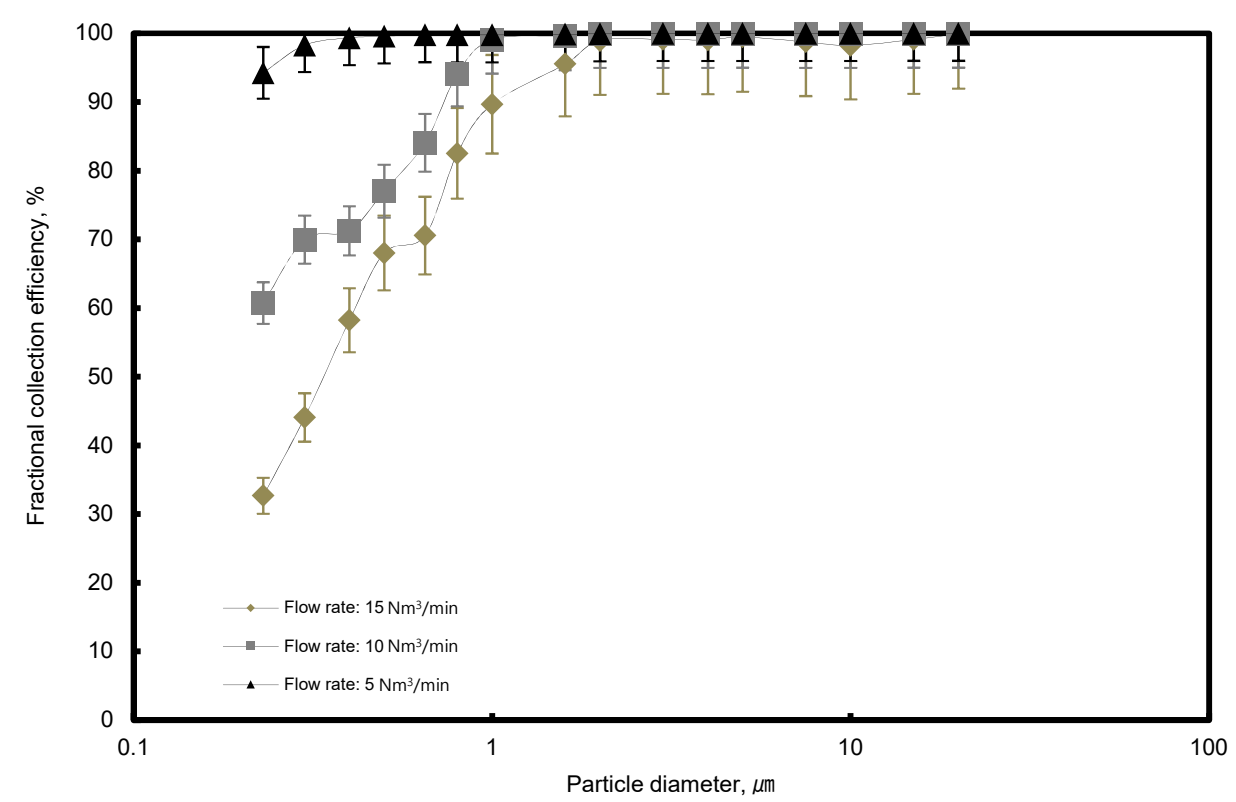

Figure 9. Fractional collection efficiency results with flow rate variable. 


\subsection{Image Analysis}

The photos of the filter used in this research before and after the experiment are shown in Figure 10. For a correct image analysis, the images before and after the experiment with SEM are shown in Figure 11. From a 1000 times magnification with SEM, we have checked that the aerosol is captured between the fibers of the filter after the experiment.

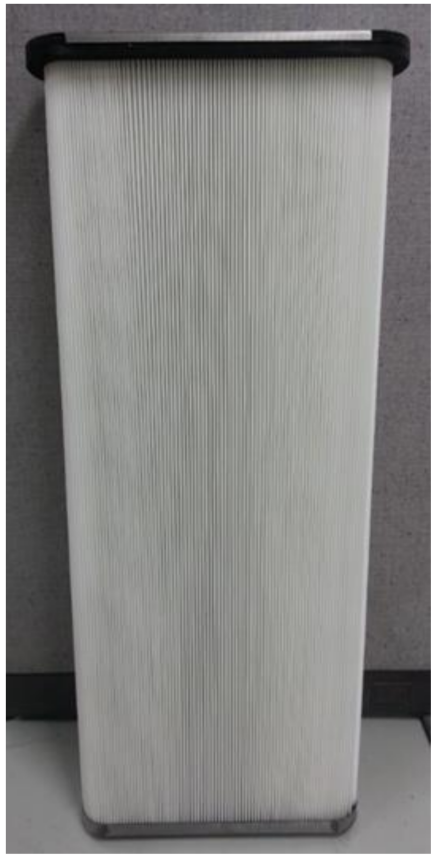

(a)

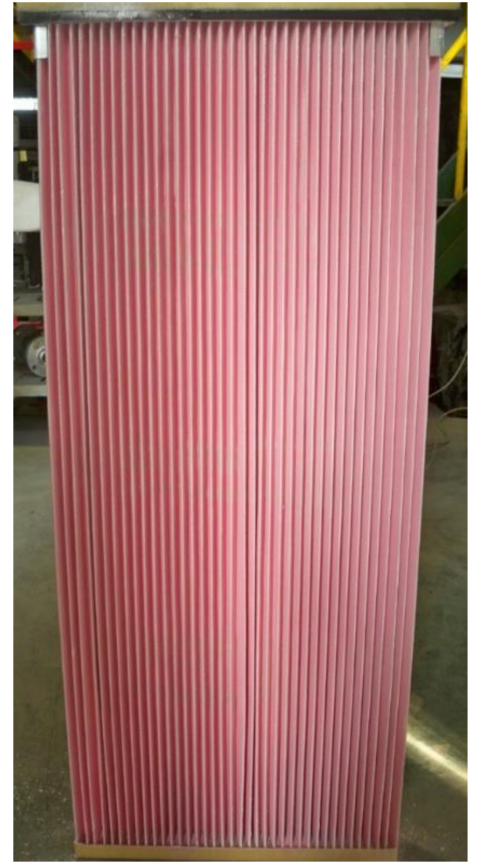

(b)

Figure 10. Photos of filters (a) before and (b) after the experiment.

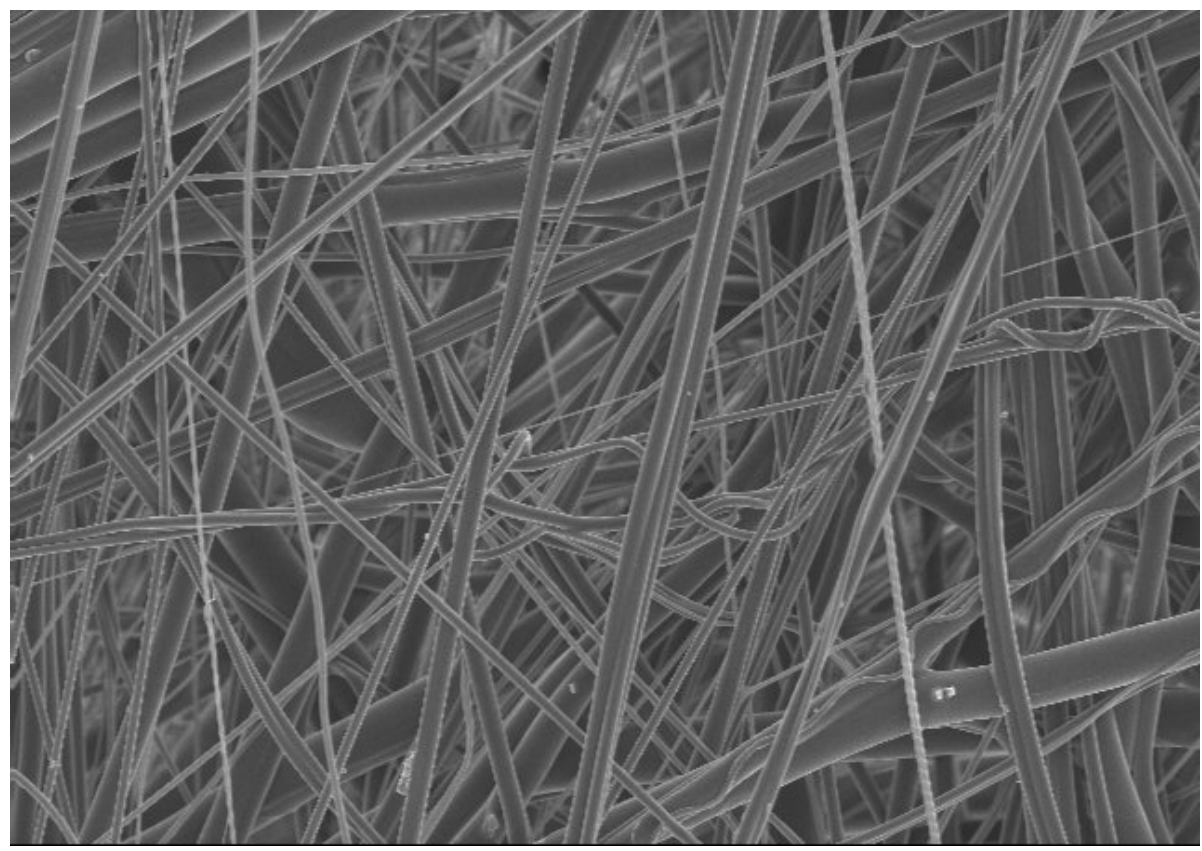

(a)

Figure 11. Cont. 


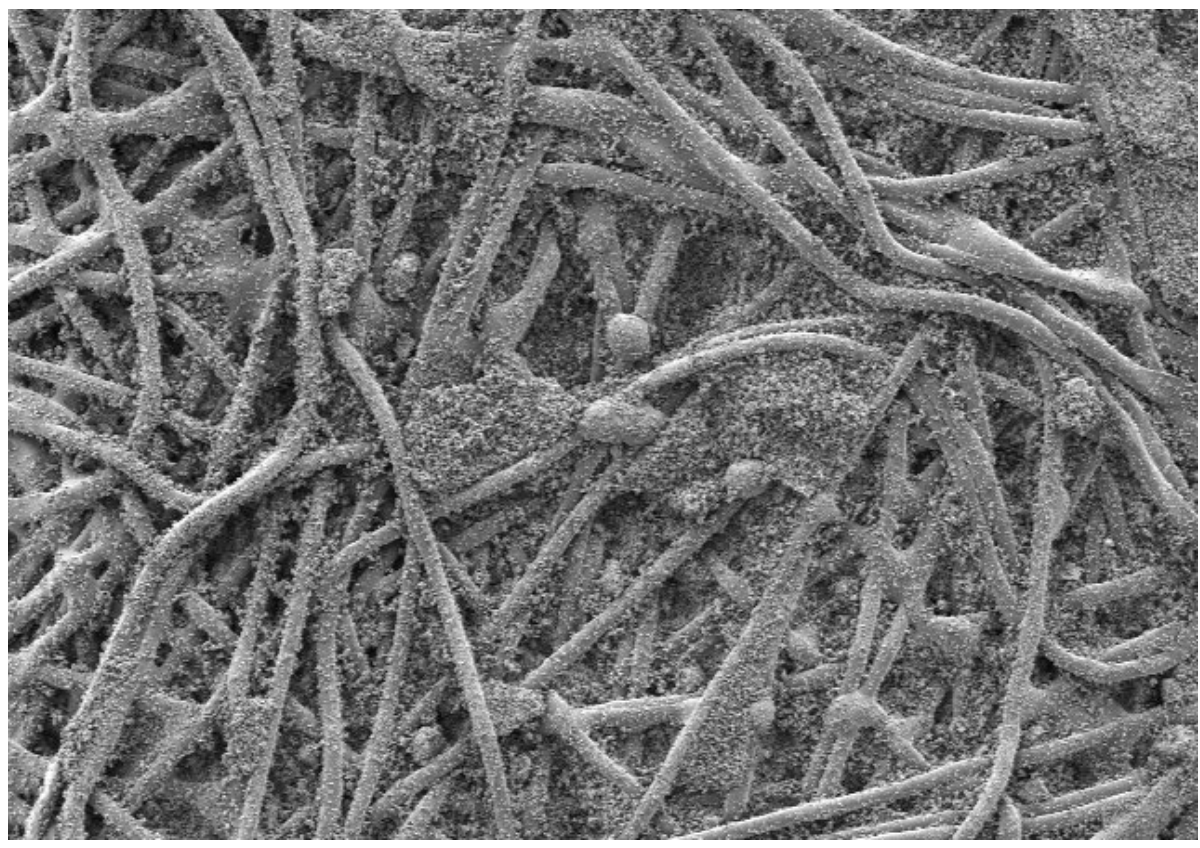

(b)

Figure 11. 1000 times magnified photos of filter media (a) before and (b) after the experiment.

\section{Conclusions}

This research has imitated an actual painting facility for removing sticky aerosol and conducted an experiment applicable to industrial settings. The sticky aerosol has been agglomerated with calcium hydroxide to lose stickiness, collected by a filter and collected in a hopper. The experiment has been carried out with variable flow rates of 5,10 , and $15 \mathrm{Nm}^{3} / \mathrm{min}$, showing the following trend: the lower the flow rate, the longer the cleaning interval. The residual pressure drop is low, while the cleaning efficiency is high. The total and fractional collection efficiency with aerosol sizes from 0.3 to $20 \mu \mathrm{m}$ showed high values at low flow rates. From the observation of images of the filter before and after the experiment, we checked that the aerosol is well captured. However, at flow rates that were lower than the experimental conditions, the aerosol sank, making the experiment impossible. Based on the results of this research, we confirm that this research is applicable for operations that generate sticky aerosol.

Author Contributions: Conceptualization, J.-R.L.; Investigation, N.H., K.-S.L. and K.-D.K.; Project administration, Y.-O.P.; Software, S.-M.J. and J.-H.G.; Supervision, K.-Y.L. and Y.-O.P.; Writing-original draft, J.-R.L.; Writing-review \& editing, J.-R.L.

Funding: This subject is supported by Korea Ministry of Environment as "Eco Business Advancement Tech Development Business".

Conflicts of Interest: The authors declare no conflict of interest.

\section{References}

1. Pope, C.A., III; Burnett, R.T.; Thun, M.J.; Calle, E.E.; Krewski, D.; Ito, K.; Thurston, G.D. Lung cancer cardiopulmonary mortality and long-term exposure to fine particulate air pollution. JAMA 2002, 287, 1132-1141. [CrossRef]

2. Feng, L.; Jianlei, N.; Zhang, L. A physically-based model for prediction of VOCs emissions from paint applied to an absorptive substrate. Build. Environ. 2006, 41, 1317-1325.

3. Joe, Y.H.; Shim, J.; Shin, W.G.; Park, H.S. Simple self-diagnostic method to identify the abnormal functioning of a scanning mobility particle sizer. J. Aerosol Sci. 2017, 114, 130-138. [CrossRef]

4. Zhang, G.S.; Li, T.T.; Luo, M.; Liu, J.F.; Liu, Z.R.; Bai, Y.H. Air pollution in the microenvironment of parked new cars. Build. Environ. 2008, 43, 315-319. [CrossRef] 
5. Sibanda, V.; Greenwood, R.W.; Seville, J.P.K. Particle separation from gases using cross-flow filtration. Powder Technol. 2001, 118, 193-202. [CrossRef]

6. Huang, S.L.; Yin, C.Y.; Yap, S.Y. Particle size and metals concentrations of dust from a paint manufacturing plant. J. Hazard. Mater. 2010, 174, 839-842. [CrossRef] [PubMed]

7. LaPuma, P.T.; Joseph, M.F.; Edgar, C.K. Chromate concentration bias in primer paint particles. Regul. Toxicol. Pharmacol. 2001, 33, 343-349. [CrossRef] [PubMed]

8. Gondal, M.A.; Hussain, T. Determination of poisonous metals in wastewater collected from paint manufacturing plant using laser-induced breakdown spectroscopy. Talanta 2007, 71, 73-80. [CrossRef] [PubMed]

9. Lambourne, R.; Strivens, T.A. (Eds.) Paint and Surface Coatings: Theory and Practice; Elsevier: Amsterdam, The Netherlands, 1999.

10. Koponen, I.K.; Jensen, K.A.; Schneider, T. Sanding dust from nanoparticle-containing paints: Physical characterisation. J. Phys. Conf. Ser. 2009, 151, 012048. [CrossRef]

11. Lee, K.S.; Hasolli, N.; Jeon, S.M.; Lee, J.R.; Kim, K.D.; Park, Y.O.; Hwang, H.J. Filter layer structure effect on the most penetrating particle size of multilayered flat sheet filter. Powder Technol. 2019, 344, 270-277. [CrossRef]

12. Kim, J.H.; Kim, Y.C.; Choi, J.H. Characteristics of pressure drop during the pulse-jet cleaning of a ceramic filter for high temperature and high pressure. Korean J. Chem. Eng. 2016, 33, 726-734. [CrossRef]

13. Park, Y.O.; Kim, K.S.; Son, J.E.; Rhee, Y.W.; Choi, W.S. Demonstration of a KIER-Type CYBAGFILTER system at the clinker calcination process. Korean J. Chem. Eng. 2000, 17, 579-584. [CrossRef]

14. Ellenbecker, M.J.; Leith, D. Dust removal characteristics of fabrics used in pulse-jet filters. Powder Technol. 1983, 36, 13-19. [CrossRef]

15. Lee, K.S.; Sohn, J.R.; Park, Y.O. Filtration performance characteristics of ceramic candle filter based on inlet structure of high-temperature and high-pressure dust collectors. J. Ind. Eng. Chem. 2015, 21, 101-110. [CrossRef]

16. Shim, J.M.; Joe, Y.H.; Park, H.S. Influence of air injection nozzles on filter cleaning performance of pulse-jet bag filter. Powder Technol. 2017, 322, 250-257. [CrossRef]

17. Lu, H.C.; Tsai, C.J. A pilot-scale study of the design and operation parameters of a pulse-jet baghouse. Aerosol Sci. Technol. 1998, 29, 510-524. [CrossRef]

18. Chen, Y.S.; Hsiau, S.S.; Lai, S.C.; Chyou, Y.P.; Li, H.Y.; Hsu, C.J. Filtration of dust particulates with a moving granular bed filter. J. Hazard. Mater. 2009, 171, 987-994. [CrossRef] [PubMed]

19. Leung, W.W.F.; Hung, C.H.; Yuen, P.T. Effect of face velocity nanofiber packing density and thickness on filtration performance of filters with nanofibers coated on a substrate. Sep. Purify. Technol. 2010, 71, 30-37. [CrossRef]

20. Kanaoka, C.; Emi, H.; Myojo, T. Simulation of the growing process of a particle dendrite and evaluation of a single fiber collection efficiency with dust load. J. Aerosol Sci. 1980, 11, 377-389. [CrossRef]

21. Brown, R.C.; Wake, D. Loading filters with monodisperse aerosols: Macroscopic treatment. J. Aerosol Sci. 1999, 30, 227-234. [CrossRef]

(c) 2019 by the authors. Licensee MDPI, Basel, Switzerland. This article is an open access article distributed under the terms and conditions of the Creative Commons Attribution (CC BY) license (http://creativecommons.org/licenses/by/4.0/). 